\title{
Comparison of Three Different Options for C7 Posterior Vertebral Anchor in the Indian Population- Lateral Mass, Pedicle, and Lamina: A Computed Tomography-Based Morphometric Analysis
}

\author{
Vibhu Krishnan Viswanathan ${ }^{1}$, Surabhi Subramanian ${ }^{2}$, Sushma Viswanathan ${ }^{3}$ \\ ${ }^{1}$ Department of Neurological Surgery, The Ohio State University Wexner Medical Center, Columbus, Ohio, USA \\ ${ }^{2}$ Department of Radiodiagnosis, Government Medical College and Hospital, Nagpur, Maharashtra, India \\ ${ }^{3}$ Department of Mental Health, Sri Ramachandra Medical College and Research Institute, Chennai, India
}

\section{Study Design: Radiological cohort study.}

Purpose: The options of posteriorly stabilizing C7 vertebra include using lateral mass, pedicle or lamina, as bony anchors. The current study is a computed tomography (CT)-based morphometric analysis of C7 vertebra of 100 Indian patients and discusses the feasibility of these different techniques.

Overview of Literature: $\mathrm{C7}$ is a peculiar vertebra with unique anatomy, which poses challenges for each of these fixation modalities. There are no reports available in the literature, which discuss and compare the feasibility of diverse posterior C7 fixation techniques in Indian population.

Methods: We included 100 consecutive cervical spine CT scans of Indian patients performed between July 2016 and September 2016. We excluded CT scans with any significant congenital anomaly or other pathological lesions of C7 and patients with non-Indian ethnicity. Regarding screw placement, we assessed and studied various dimensions of the $\mathrm{C} 7$ lateral mass, pedicles, and laminae in relevant sections. Results: The mean age of our patients was $49.5 \pm 16.1$ years. We included 56 male and 44 female patients. The mean anteroposterior and mediolateral dimensions of the lateral mass were $11.38 \pm 1.76$ and $12.91 \pm 1.82 \mathrm{~mm}$, respectively. The mean length of the lateral mass screw (Magerl technique) was $12.17 \pm 1.9 \mathrm{~mm}$; $92 \%$ of patients could accommodate a lateral mass screw at least 10-mm long (unicortical), whereas $48 \%$ could accommodate a screw (unicortical) longer than $12 \mathrm{~mm}$. Foramen transversarium was found in $30.5 \%$ of lateral masses. The mean outer and inner cortical widths of the pedicles were $6.5 \pm 0.71 \mathrm{~mm}$ and $3.72 \pm 0.61 \mathrm{~mm}$, respectively. Approximately $58 \%$ of pedicles could accommodate $3.5-\mathrm{mm}$ screws (based on the inner cortical pedicle width). The outer cortical and inner cortical widths of the laminae were $6.21 \pm 1.2 \mathrm{~mm}$ and $3.23 \pm 0.9 \mathrm{~mm}$, respectively. Subsequently, $37 \%$ of the laminae could accommodate 3.5-mm screws. The mean angle of intralaminar screw trajectory was $50.7^{\circ} \pm 5.1^{\circ}$, and the mean length of the intralaminar screw was $32.6 \pm 3.05 \mathrm{~mm}$. In addition, $96.4 \%$ and $60.7 \%$ of male patients could accommodate lateral mass screws longer than $10 \mathrm{~mm}$ and $12 \mathrm{~mm}$, respectively. However, only $86.4 \%$ and $31.8 \%$ of female patients could accommodate 10 - and 12-mm long lateral mass screws, respectively. Furthermore, $75 \%$ of male patients and $36 \%$ of female patients had pedicles that could accommodate $3.5-\mathrm{mm}$ diameter screws, and $48.2 \%$ of male patients had laminae that could accommodate $3.5-\mathrm{mm}$ screws; however, only $22.7 \%$ of female patients could accommodate 3.5-mm laminar screws.

Conclusions: Based on our CT-guided morphometric analysis, 92\% and 48\% of Indian patients could accommodate at least 10- and 12mm long lateral mass screws, and $58 \%$ of pedicles and $37 \%$ of laminae could accommodate 3.5 -mm screws. Thus, lateral mass screws (between 10- and 12-mm long) seem to be the safest feasible option for $\mathrm{C7}$ fixation. In case of the need for an alternative mode of stabilization (pedicle or intralaminar screw), particularly in female patients, careful preoperative planning with a CT scan is of utmost importance.

Keywords: Cervical vertebrae; Cervicothoracic fusion; Vertebra stabilization; Vertebral screws; Pedicle screws

Received Oct 12, 2017; Revised Dec 2, 2017; Accepted Dec 21, 2017

Corresponding author: Surabhi Subramanian

Department of Radiology, Government Medical College and Hospital, Nagpur, Maharashtra 440003, India

Tel: +91-9405874910, E-mail: subramaniansurabhi@gmail.com 


\section{Introduction}

Posterior cervical spine stabilization is currently a popular cervical fusion technique and is considered as an adjunct or alternative to anterior fusion in certain conditions, such as multilevel vertebral pathologies, spinal tumors, complex spinal deformities, and pathologies at the cervicothoracic levels, particularly in patients with difficult access through anterior approach [1].

Compared with the other six vertebrae, C7 is unique because of its peculiar anatomy of pedicles, laminae, and foramen transversarium; junctional location; resemblance to thoracic vertebrae; and inconsistent relationship to the vertebral artery [2]. Nevertheless, the inevitability of securing a stable anchor at the $\mathrm{C} 7$ level cannot be understated in cervicothoracic fusions; the current options of screw fixation at $\mathrm{C} 7$ include pedicles, laminae, and lateral masses [3]. Various reports have discussed the advantages and disadvantages of each of these options in the literature, including the preference for different fixation modalities based on the demographic profile of the patient population [2-4]. Reports comparing these three C7 stabilization modalities in the Indian population are currently not available. The present study is a computed tomography (CT)-based morphometric analysis of C7 lateral masses, pedicles, and laminae, wherein we analyze the feasibility of fixation with screws using each of these anchors.

\section{Materials and Methods}

We included 100 consecutive cervical spine CT scans of Indian patients aged 18-70 years performed between July 2016 and September 2016. And informed consent was obtained from all patients. We excluded scans with any significant congenital anomaly of $\mathrm{C} 7$, fractures, or other C7 pathological lesions as well as patients with non-Indian ethnicity. All CT scans were performed using Philips 128 slice multiple detector CT (Philips Health Care, Amsterdam, Netherlands). Sagittal and coronal reconstructions were obtained, and $1.25-\mathrm{mm}$ slice thickness were recorded.

All CT scans were assessed and measured by a single radiologist. The measurements were performed on standard axial and sagittal sections and further reformatted on a three-dimensional model. We measured the lateral mass screw trajectories and dimensions with the Magerl technique [5]. The starting point of the screw was $1 \mathrm{~mm}$ medial and superior to the center of the posterior lateral mass and was directed superiorly at $45^{\circ}$ on the sagittal sections and laterally at $25^{\circ}$ on the axial sections. A straighter or more medially directed trajectory was obtained for lateral masses containing foramen transversarium. The anteroposterior (AP) and mediolateral (ML) dimensions of lateral masses were measured on the sagittal and axial sections at the point of maximum size. The pedicles were similarly measured: angles of the pedicle screw trajectories (angle between the angle of the axis of the pedicles and midline), mean length of the longest pedicle screw; and inner and outer cortical widths of the pedicles (described by Karaikovic et al. [6]) on axial sections of the CT scan. The width of the pedicle/lamina measured between the two inner and outer cortices was described as the inner and outer cortical widths, respectively (Fig. 1). Laminar dimensions, including inner and outer cortical widths of the laminae and the angles of laminar screw trajectories (angle between the angle of the axis of the laminae and midline), and mean length of the longest intralaminar screw were measured [3].

The mean of all these dimensions was obtained and analyzed. Statistical analysis was performed using IBM SPSS software ver. 20.0 (IBM Corp., Armonk, NY, USA). Normality of the data was tested using Shapiro-Wilk test. Chi-square test was used for categorical variables, whereas Student $t$-test or Mann-Whitney test was used for quantitative variables. A $p$-value of $<0.05$ was considered statistically significant.

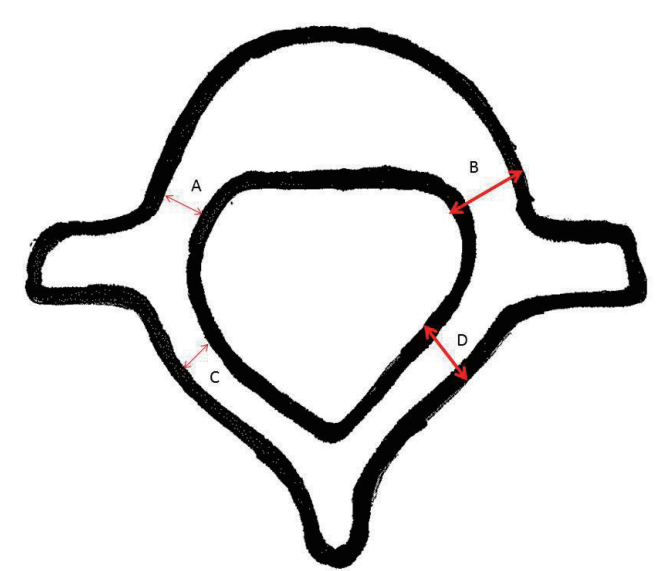

Fig. 1. C7 axial sections measuring the (A) inner and (B) outer cortical widths of the pedicle and (C) inner and (D) outer cortical widths of the lamina. 
Table 1. Lateral mass screw dimension

\begin{tabular}{|c|c|c|c|c|c|c|c|}
\hline \multirow{2}{*}{ Parameter } & \multicolumn{7}{|c|}{ Dimension } \\
\hline & Mean & Male & Female & $p$-value & Right & Left & $p$-value \\
\hline Anteroposterior dimension of lateral mass (mm) & $11.38 \pm 1.76$ & $12.1 \pm 1.72$ & $10.46 \pm 1.33$ & 0.000 & $11.35 \pm 1.77$ & $11.41 \pm 1.76$ & 0.81 \\
\hline Mediolateral dimension of lateral mass (mm) & $12.91 \pm 1.82$ & $13.64 \pm 1.74$ & $11.98 \pm 1.47$ & 0.000 & $12.9 \pm 1.83$ & $12.92 \pm 1.83$ & 0.95 \\
\hline Mean lateral mass screw length (mm) & $12.17 \pm 1.9$ & $12.775 \pm 2.08$ & $11.41 \pm 1.3$ & 0.001 & $12.13 \pm 1.94$ & $12.21 \pm 1.87$ & 0.91 \\
\hline Presence of foramen transversarium (patients) & 30.5 & 33.0 & 27.3 & 0.519 & 31.0 & 30.0 & 1.000 \\
\hline $\begin{array}{l}\text { Proportion of lateral masses that may accommodate } \\
\text { screws }>10 \mathrm{~mm} \text { long (\%) }\end{array}$ & 92.0 & 96.4 & 86.4 & & 92.0 & 92.0 & \\
\hline $\begin{array}{l}\text { Proportion of lateral masses that may accommodate } \\
\text { screws }>12 \mathrm{~mm} \text { long }\end{array}$ & 48.0 & 60.7 & 31.8 & & 48.0 & 48.0 & \\
\hline
\end{tabular}

Values are presented as mean \pm standard deviation or $\%$.

Table 2. Pedicle screw dimension

\begin{tabular}{|c|c|c|c|c|c|c|c|}
\hline \multirow{2}{*}{ Parameter } & \multicolumn{7}{|c|}{ Dimension } \\
\hline & Mean & Male & Female & $p$-value & Right & Left & $p$-value \\
\hline Outer cortical width of the pedicle (mm) & $6.5 \pm 0.71$ & $6.71 \pm 0.74$ & $6.21 \pm 0.56$ & 0.000 & $6.48 \pm 0.74$ & $6.5 \pm 0.69$ & 0.845 \\
\hline Inner cortical width of the pedicle (mm) & $3.72 \pm 0.61$ & $3.89 \pm 0.61$ & $3.51 \pm 0.54$ & 0.001 & $3.71 \pm 0.64$ & $3.73 \pm 0.6$ & 0.832 \\
\hline Proportion of pedicles that may accommodate 3.5-mm screws (\%) & 58 & 75 & 36 & & 56 & 60 & \\
\hline Mean angles of the pedicle screw trajectory $\left(^{\circ}\right)$ & $33.8 \pm 7.5$ & $34.1 \pm 7.15$ & $33.5 \pm 7.95$ & 0.982 & $33.45 \pm 8.12$ & $34.17 \pm 6.84$ & 0.782 \\
\hline Mean lengths of the pedicle screw $(\mathrm{mm})$ & $29.9 \pm 7.7$ & $31.5 \pm 8.5$ & $27.9 \pm 5.9$ & 0.000 & $29.9 \pm 7.61$ & $30.1 \pm 7.8$ & 0.694 \\
\hline
\end{tabular}

Values are presented as mean \pm standard deviation or $\%$.

\section{Results}

The mean age of our patients was $49.5 \pm 16.1$ years. We included 56 male and 44 female patients. The mean AP and ML dimensions of the lateral mass were $11.38 \pm 1.76$ and $12.91 \pm 1.82 \mathrm{~mm}$, respectively (Table 1 , Fig. 2 ). The mean length of the lateral mass screw (Magerl technique) was $12.17 \pm 1.9 \mathrm{~mm}$. The mean AP $(10.46 \pm 1.33 \mathrm{~mm}$ versus $12.1 \pm 1.72 \mathrm{~mm}, p=0.000)$ and $\mathrm{ML}(11.98 \pm 1.47 \mathrm{~mm}$ versus $13.64 \pm 1.74 \mathrm{~mm}, p=0.000)$ dimensions of the lateral mass and mean lateral mass screw length $(11.41 \pm 1.3 \mathrm{~mm}$ versus $2.77 \pm 2.08 \mathrm{~mm}, p=0.000$ ) were significantly smaller in female patients than in male patients. No statistically significant difference was found between these parameters in the right and left lateral masses $(p=0.81, p=0.95$, and $p=0.91$ for $\mathrm{AP}$ and $\mathrm{ML}$ dimensions of the lateral mass and length of lateral mass screw). A patent foramen transversarium was found in $30.5 \%$ of the lateral masses. Further, $96.4 \%$ of lateral masses in male patients could accommodate 10 -mm long unicortical screws, whereas $60.7 \%$ accommodated 12-mm unicortical screws. Moreover, $86.4 \%$

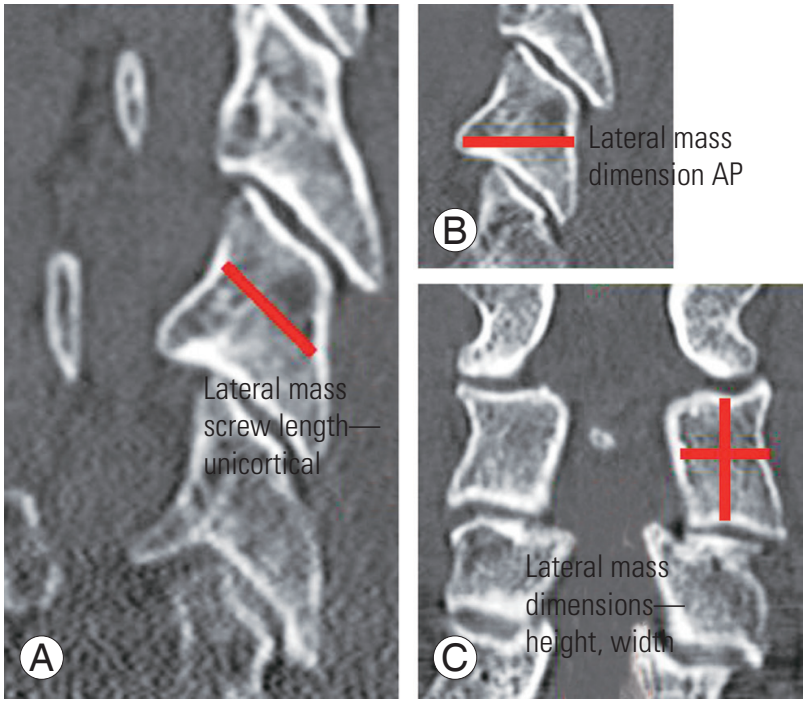

Fig. 2. (A) Sagittal section of lateral mass at the midsagittal plane demonstrating the length of lateral mass screw (Magerl technique). (B) Sagittal section of the lateral mass at the midsagittal plane demonstrating the AP length of the lateral mass. (C) Coronal section of the lateral mass at the midcoronal plane demonstrating the mediolateral and cephalocaudal (height) lengths of the lateral mass. AP, anteroposterior. 
of lateral masses in female patients could accommodate $10-\mathrm{mm}$ unicortical screws, whereas only $31.8 \%$ accommodated 12-mm unicortical screws. Overall, 10-mm unicortical lateral mass screws could be safely accommodated in $92.5 \%$ of Indian patients and $12-\mathrm{mm}$ unicortical screws in only $48 \%$.

The pedicular dimensions were measured (Table 2, Fig. $3)$; the mean outer and inner cortical widths were $6.5 \pm 0.71$ and $3.72 \pm 0.6 \mathrm{~mm}$, respectively. Both these measurements were also significantly smaller in female patients (outer cortical width: $6.21 \pm 0.56 \mathrm{~mm}$ versus $6.71 \pm 0.74 \mathrm{~mm}$, $p=0.000$ and inner cortical width: $3.51 \pm 0.54 \mathrm{~mm}$ versus $3.89 \pm 0.6 \mathrm{~mm}, p=0.001)$. The right and left pedicles were similar with respect to these dimensions.

Approximately $58 \%$ of pedicles could accommodate a 3.5-mm pedicle screw (based on the inner cortical width). Only $36 \%$ of female patients could safely accommodate 3.5- $\mathrm{mm}$ pedicle screws (i.e., inner cortical dimension $\geq 3.5$ $\mathrm{mm}$ ) compared with $75 \%$ of male patients who could accommodate pedicle screws of such dimension. The mean
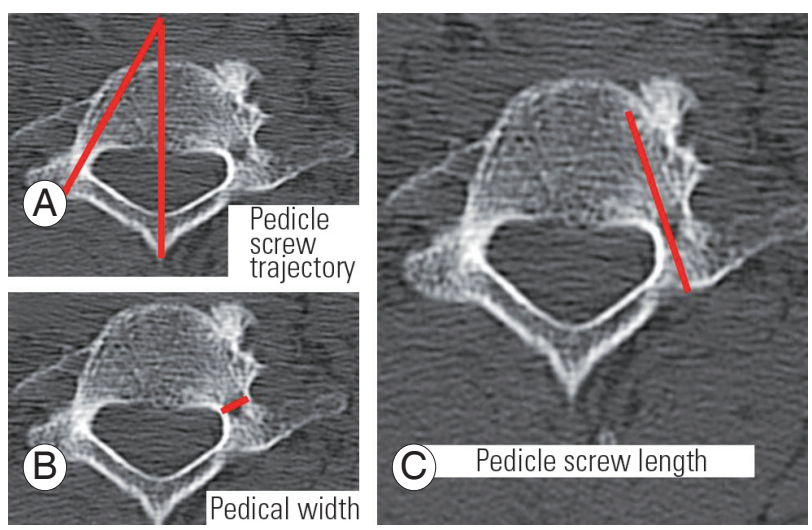

Fig. 3. (A) C7 axial sections measuring the angle of the pedicle screw trajectory, (B) width of the pedicle, and (C) length of the pedicle screw. angle of the pedicle screw trajectory was $33.8^{\circ} \pm 7.5^{\circ}$, and the mean length of the pedicle screw was $29.9 \pm 7.7 \mathrm{~mm}$. The mean pedicle screw length was significantly shorter in female patients than in male patients $(27.9 \pm 5.9 \mathrm{~mm}$ versus $3.5 \pm 8.5 \mathrm{~mm}, p=0.000$ ).

Similarly, the lamina was measured based on CT scans (Table 3, Fig. 4). The outer cortical and inner cortical widths measured $6.21 \pm 1.2 \mathrm{~mm}$ and $3.23 \pm 0.9 \mathrm{~mm}$, respectively. Regarding the laminar dimensions, the female patients had significantly smaller outer $(5.86 \pm 0.9 \mathrm{~mm}$ versus
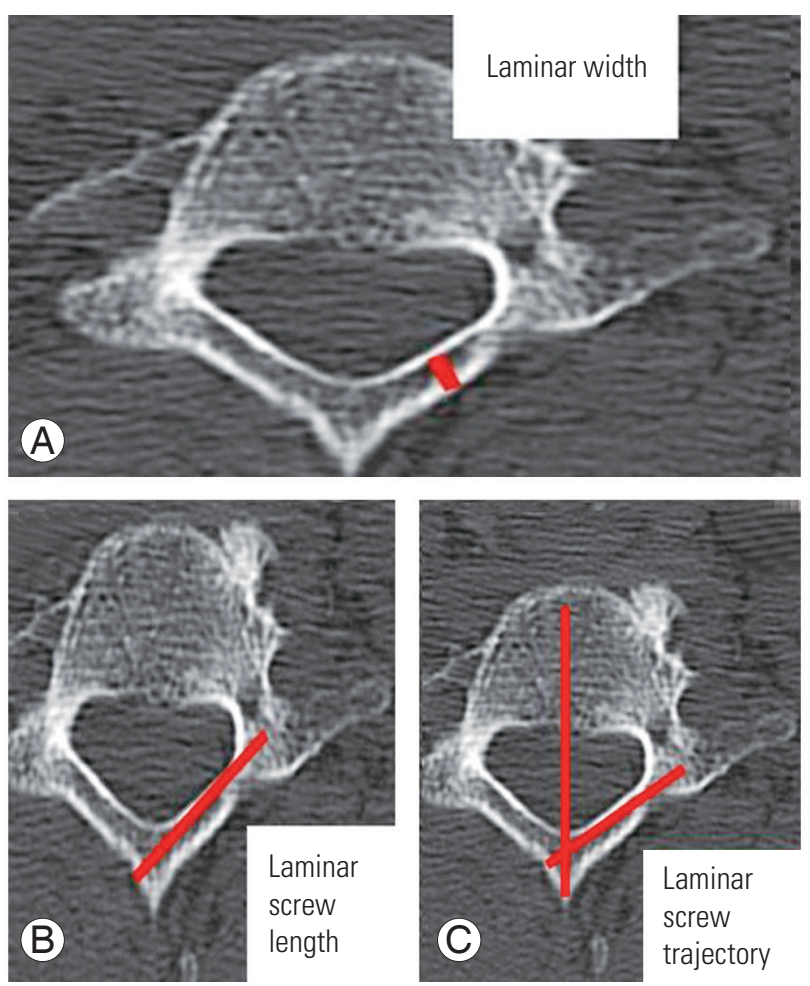

Fig. 4. (A) C7 axial sections measuring the laminar width. (B) Sagittal section of the lamina of C7 demonstrating the laminar height. (C) C7 axial sections measuring the length of the laminar screw and (D) angle of the laminar screw trajectory.

Table 3. Laminar screw dimension

\begin{tabular}{|c|c|c|c|c|c|c|c|}
\hline \multirow{2}{*}{ Parameter } & \multicolumn{7}{|c|}{ Dimension } \\
\hline & Mean & Male & Female & $p$-value & Right & Left & $p$-value \\
\hline Outer cortical width of the lamina & $6.21 \pm 1.2$ & $6.5 \pm 1.4$ & $5.86 \pm 0.9$ & 0.01 & $6.19 \pm 1.3$ & $6.22 \pm 1.18$ & 0.876 \\
\hline Inner cortical width of the lamina & $3.23 \pm 0.9$ & $3.39 \pm 1.07$ & $3.02 \pm 0.6$ & 0.046 & $3.18 \pm 0.9$ & $3.27 \pm 0.9$ & 0.61 \\
\hline Proportion of laminae that may accommodate $3.5-\mathrm{mm}$ screws (\%) & 37.0 & 48.2 & 22.72 & & 38.0 & 36.0 & \\
\hline Mean angles of intralaminar screw trajectory & $50.7 \pm 5.1$ & $49.04 \pm 4.7$ & $52.74 \pm 4.9$ & 0.001 & $50.7 \pm 5.2$ & $50.6 \pm 5.1$ & 0.985 \\
\hline Mean lengths of the intralaminar screw & $32.6 \pm 3.05$ & $34.07 \pm 2.08$ & $30.8 \pm 3.13$ & 0.000 & $32.6 \pm 2.9$ & $32.62 \pm 3.22$ & 0.287 \\
\hline
\end{tabular}

Values are presented as mean \pm standard deviation or $\%$. 
$6.5 \pm 1.4 \mathrm{~mm}, p=0.01)$ and inner cortical widths $(3.02 \pm 0.6$ versus $3.39 \pm 1.07 \mathrm{~mm}, p=0.046$ ). Only $37.5 \%$ of the laminae could accommodate $3.5-\mathrm{mm}$ screws (based on the dimension of the inner cortical width). In female patients, only $22.72 \%$ of the laminae could accommodate $3.5-\mathrm{mm}$ screws. The mean angle of intralaminar screw trajectory was $50.7 \pm 5.1 \mathrm{~mm}$. The mean length of the intralaminar screw was $32.6 \pm 3.05 \mathrm{~mm}$. The mean length of the laminar screw was significantly shorter in female patients $(p=0.000)$. The right and left laminae were similar with respect to all these parameters.

\section{Discussion}

The C7 vertebra is a transitional vertebra, and its anatomy is unique compared with the other subaxial vertebrae $[2,3]$. However, fixation at C7 is an important part of any construct spanning the cervicothoracic junction [7]. The options of screw fixation at C7 include lateral mass, pedicle, and intralaminar screws. The intralaminar screw technique is currently used as a salvage procedure, in situations wherein a good anchor at the lateral mass or pedicle is unavailable [8]. Careful preoperative planning with appropriate investigational modalities is of utmost importance before $\mathrm{C} 7$ fixation because of the peculiar, variable anatomy of lateral masses and pedicles at $\mathrm{C} 7$ and its inconsistent relationship to the vertebral artery [9]. However, understanding the general anatomic profile of C7 vertebral elements for any demographic patient population also provides us with the basic knowledge in these situations [2]. Currently, no studies have reported the morphometric analysis of C7 in the Indian population. The present study is a CT-based analysis of 100 Indian patients wherein we discussed the anatomy of C7 vertebral elements in relation to lateral mass, laminar, and pedicle screw techniques.

C7 fixation may be an inevitable component in posterior cervical or cervicothoracic stabilization [10]. Although lateral mass fixation is the gold standard for C3C6 fixations, the C7 lateral mass has been considered less conducive for screw fixation. It has been postulated that this occurs secondary to a greater intrusion ratio, which is defined as the proportion of the C7 lateral mass involved in articulation with $\mathrm{T} 1$ facet (intrusion) divided by the overall sagittal length of the lateral mass $[7,11]$. This means that the effective sagittal surgical space available for a C7 lateral mass may be less than that for lateral masses at other subaxial levels. However, a good C7 lateral mass screw can preclude the need for extending cervical fusion to the T1 level [12]. It can also help the surgeon align the C7 screw well in relation to the C6 lateral mass screw compared with a $\mathrm{C} 7$ pedicle screw, which may require skipping a screw at the C6 level [2,3]. CT scans showed that unicortical lateral mass screws (using Magerl technique) longer than $10 \mathrm{~mm}$ and $12 \mathrm{~mm}$ could be safely accommodated in $92 \%$ and $48 \%$ of Indian patients, respectively. Thus, a good length lateral mass screw can be safely used in a good proportion of Indian patients. In addition, 10 - $\mathrm{mm}$ screws were feasible in $96.4 \%$ and $86.4 \%$ of male and female patients, respectively, and $60.7 \%$ and $31.8 \%$ of male and female patients could undergo fixation using lateral mass screws $12 \mathrm{~mm}$ or longer. The overall mean lateral mass screw length was $12.17 \mathrm{~mm}$, indicating that a lateral mass screw between $10 \mathrm{~mm}$ and $12 \mathrm{~mm}$ is a safe feasible option in a majority of male and female Indian patients. Screws longer than $10 \mathrm{~mm}$ were feasible in only $<50 \%$ of the overall population (only $31.8 \%$ of female patients).

C7 pedicle screw fixation is an alternative popular modality $[1,13]$. This technique can be used in situations where the lateral mass may be unable to accommodate a good screw length, particularly in the elderly population; the sagittal length of the lateral mass and thereby the effective surgical space available for this technique becomes smaller and inadequate due to repeated degenerative process [11]. However, the use of the C7 pedicle screw precludes lateral mass fixation at the $\mathrm{C} 6$ level. The $\mathrm{C} 7$ pedicle screw carries a risk for C8 nerve root injury, which predominantly affects major hand functions $[2,14]$. Pedicle screw fixation may also be technically difficult in C7 with patent foramen transversarium as such foramina can potentially contain the vertebral artery [1]. A patent foramen transversarium at the C7 level was found in 30.5\% of patients, indicating the utmost need for careful preoperative planning, particularly for pedicular screw placement, which was much higher than the rates reported in the literature $(7.5 \%$ of the $\mathrm{C} 7$ vertebrae may contain a vertebral artery) [1]. We measured the inner and outer cortical widths of the pedicle and included only the pedicles with inner cortical dimension $>3.5 \mathrm{~mm}$ as "safe" vertebrae to accommodate $3.5-\mathrm{mm}$ pedicle screws. Although we understand that pedicle screws can be inserted even in pedicles of smaller dimension (if the outer cortical width $>3.5$ $\mathrm{mm}$ ), we only included the inner cortical width as the 
critical dimension to be considered in our study. With this criterion, we observed that $58 \%$ of pedicle screws could be considered "safe." The mean angle of pedicle screw trajectory was $33.8^{\circ}$, and the mean length was $29.9 \mathrm{~mm}$. Thus, pedicle screws could provide a longer anchor at $\mathrm{C} 7$ than the lateral mass screws in a carefully selected proportion of the population. Nevertheless, this modality may not be as safe in female patients compared with their male counterparts, considering the much smaller inner cortical dimensions in Indian females. Approximately $75 \%$ of male patients could accommodate a good-sized pedicle screw. This implies the need for careful preoperative planning, particularly in female patients, before using C7 pedicle screws. Another weakness of C7 pedicle screw insertion is the presence of sclerotic pedicles. A recent study by Kato et al. [15] observed that the incidence of sclerotic pedicles in the cervical spine varied between $7.3 \%$ in patients with cervical spondylomyelopathy and $23 \%$ in patients with athetoid cerebral palsy. They also observed a significantly higher incidence of breach of sclerotic cervical pedicles. Such pedicles may therefore not accommodate screw insertion. We did not separately assess the incidence of pedicle sclerosis in our study.

Intralaminar screws have been considered as a safe, salvage modality when conventional cervical fixation techniques fail [3]. Although in C7, studies have indicated similar pull-out strengths as transpedicular fixation, laminar screws may pose a technical difficulty in connecting to a good lordotic, contoured rod [8]. Regarding the pedicle screws, we included only the laminae with inner cortical dimension $>3.5 \mathrm{~mm}$ as "safe" vertebrae to accommodate $3.5-\mathrm{mm}$ intralaminar screws. Only $37 \%$ of our patients could safely accommodate a C7 laminar screw. In fact, only $22.7 \%$ of our female patients could safely accommodate a $3.5-\mathrm{mm}$ laminar screw compared with $49.2 \%$ of our male patients. Although the mean length of the laminar screws was $32.6 \mathrm{~mm}$ (comparable to pedicle screws), only a small group of patients (particularly female patients) can undergo safe intralaminar screw placement (based on these findings). A preoperative CT scan to assess the laminar size is therefore mandatory.

Abumi et al. [1] studied 669 cases of cervical pedicle screw fixation and found that 45 screws (6.7\%) penetrated the cortical bone. Jeanneret et al. [5] suggested that C5 pedicle screws had the greatest chance of pedicle violation, whereas C6 and C7 screws had the lowest chance. Using their cadaveric model, $\mathrm{Xu}$ et al. [4] demonstrated that C7 lateral mass screws are biomechanically as effective as C7 pedicle screws in long subaxial constructs. However, other studies found in the literature have indicated greater biomechanical superiority of cervical pedicle screw over lateral mass fixation technique $[14,16]$. The intralaminar screw at $\mathrm{C} 7$ is also a biomechanically stable alternative described in the literature [8].

Singh et al. [17] performed a morphometric analysis of cadaveric thoracic spines in the Indian population and evaluated the size of thoracic pedicles. They observed that the midpedicle width was $<5 \mathrm{~mm}$ in $31.5 \%$ of all thoracic pedicles, $71 \%$ of $\mathrm{T} 5$ pedicles, $54.6 \%$ of all female pedicles, and $94.4 \%$ of $\mathrm{T} 5$ pedicles in female patients. Thus, they concluded that the size of thoracic pedicles in the Indian population may be smaller than that in previous reports (patients of other ethnicity); and the smallest diameter or shortest screw may be unsafe in the midthoracic spine of most of the Indian population. A recent study on subaxial cervical spine by Prabavathy et al. [18] compared the relative dimensions of all subaxial cervical vertebrae. They observed that the greatest dimensions (height, width, and length) were observed in $\mathrm{C} 3$, and the least dimensions were observed at the C7 level. Another study by Sharma et al. [19] evaluated the morphology of the axis vertebra. They observed a high variability in the thickness of the $\mathrm{C} 2$ lamina in the Indian population. Based on their observation, they concluded that the C2 lamina had smaller profiles in the Indian population than in their Western counterparts; thus, the safety of insertion of translaminar screws is low.

In our study, we observed that all three modalities are feasible options in a certain proportion of patients. The $\mathrm{C} 7$ lateral mass screw (10-12 $\mathrm{mm}$ size) is the safest feasible fixation modality in most patients. The $\mathrm{C} 7$ pedicle and intralaminar screws may offer similar biomechanical stability. Nevertheless, the anatomic variations of C7 are significant, and these alternative screws may be feasible in only $40 \%-60 \%$ of patients. The feasibility of these alternative screws is significantly less in female patients with smaller anatomic dimensions. Therefore, we strongly advocate the need for a mandatory, careful, and detailed preoperative planning (including cervical spine CT scans) before C7 fixation. We believe that the present study can help better understand the $\mathrm{C} 7$ morphology to devise a preoperative imaging protocol and plan appropriate instrumentation procedures. 


\section{Conclusions}

In our study, we observed that all three modalities are feasible options in a certain proportion of patients. C7 lateral mass screw (10-12 mm size) is the safest, feasible fixation modality in a majority of patients. C7 pedicle and intralaminar screws may offer similar biomechanical stability. Nevertheless, the anatomic variations of $\mathrm{C} 7$ are significant and these alternative screws may be feasible only in $40 \%-$ $60 \%$ of patients. The feasibility of these alternative screws is significantly less in female patients with much smaller anatomic dimensions. We therefore strongly advocate the need for a mandatory, careful and detailed, preoperative planning (including CT scans of cervical spine) prior to C7 fixation. We believe that the current study can help us in understanding the morphology of C7 vertebra, devising a preoperative imaging protocol and planning the appropriate instrumentation procedure.

\section{Conflict of Interest}

No potential conflict of interest relevant to this article was reported.

\section{Acknowledgments}

We would like to add an acknowledgment to late professor Kishor B Taori, professor and head, Department of Radiodiagnosis, Government Medical College, Nagpur, India, for his immense support and guidance in our study.

\section{References}

1. Abumi K, Shono Y, Ito M, Taneichi H, Kotani Y, Kaneda K. Complications of pedicle screw fixation in reconstructive surgery of the cervical spine. Spine (Phila Pa 1976) 2000;25:962-9.

2. Tse MS, Chan CH, Wong KK, Wong WC. Quantitative anatomy of $\mathrm{C} 7$ vertebra in Southern Chinese for insertion of lateral mass screws and pedicle screws. Asian Spine J 2016;10:705-10.

3. Jang WY, Kim IS, Lee HJ, Sung JH, Lee SW, Hong JT. A computed tomography-based anatomic comparison of three different types of $\mathrm{c} 7$ posterior fixation techniques: pedicle, intralaminar, and lateral mass screws. J Korean Neurosurg Soc 2011;50:166-72.

4. Xu R, McGirt MJ, Sutter EG, et al. Biomechanical comparison between C-7 lateral mass and pedicle screws in subaxial cervical constructs: presented at the 2009 Joint Spine Meeting: laboratory investigation. J Neurosurg Spine 2010;13:688-94.

5. Jeanneret B, Magerl F, Ward EH, Ward JC. Posterior stabilization of the cervical spine with hook plates. Spine (Phila Pa 1976) 1991;16(3 Suppl):S56-63.

6. Karaikovic EE, Daubs MD, Madsen RW, Gaines RW Jr. Morphologic characteristics of human cervical pedicles. Spine (Phila Pa 1976) 1997;22:493-500.

7. Abdullah KG, Nowacki AS, Steinmetz MP, Wang JC, Mroz TE. Factors affecting lateral mass screw placement at C-7. J Neurosurg Spine 2011;14:405-11.

8. Cardoso MJ, Dmitriev AE, Helgeson MD, et al. Using lamina screws as a salvage technique at C-7: computed tomography and biomechanical analysis using cadaveric vertebrae: laboratory investigation. J Neurosurg Spine 2009;11:28-33.

9. Stemper BD, Marawar SV, Yoganandan N, Shender BS, Rao RD. Quantitative anatomy of subaxial cervical lateral mass: an analysis of safe screw lengths for Roy-Camille and magerl techniques. Spine (Phila Pa 1976) 2008;33:893-7.

10. Desai S, Sethi A, Ninh CC, Bartol S, Vaidya R. Pedicle screw fixation of the $\mathrm{C} 7$ vertebra using an anteroposterior fluoroscopic imaging technique. Eur Spine J 2010;19:1953-9.

11. Abdullah KG, Steinmetz MP, Mroz TE. Morphometric and volumetric analysis of the lateral masses of the lower cervical spine. Spine (Phila Pa 1976) 2009;34:1476-9.

12. Yusof MI, Ming LK, Abdullah MS, Yusof AH. Computerized tomographic measurement of the cervical pedicles diameter in a Malaysian population and the feasibility for transpedicular fixation. Spine (Phila Pa 1976) 2006;31:E221-4.

13. Hasegawa K, Hirano T, Shimoda H, Homma T, Morita O. Indications for cervical pedicle screw instrumentation in nontraumatic lesions. Spine (Phila $\mathrm{Pa}$ 1976) 2008;33:2284-9.

14. Johnston TL, Karaikovic EE, Lautenschlager EP, Marcu D. Cervical pedicle screws vs. lateral mass screws: uniplanar fatigue analysis and residual pullout strengths. Spine J 2006;6:667-72.

15. Kato S, Shoda N, Chikuda H, Seichi A, Takeshita K. Morphological characteristics of cervical spine in patients with athetoid cerebral palsy and the accuracy 
of pedicle screw placement. Spine (Phila Pa 1976) 2014;39:E508-13.

16. Jones EL, Heller JG, Silcox DH, Hutton WC. Cervical pedicle screws versus lateral mass screws: anatomic feasibility and biomechanical comparison. Spine (Phila Pa 1976) 1997;22:977-82.

17. Singh R, Srivastva SK, Prasath CS, Rohilla RK, Siwach R, Magu NK. Morphometric measurements of cadaveric thoracic spine in Indian population and its clinical applications. Asian Spine J 2011;5:20-34.
18. Prabavathy G, Philip XC, Arthi G, Sadeesh T. Morphometric study of cervical vertebrae C3-C7 in South Indian population: a clinico-anatomical approach. Italian J Anat Embryol 2017;122:49-57.

19. Sharma RM, Pruthi N, Pandey P, Dawn R, Ravindranath Y, Ravindranath R. Morphometric and radiological assessments of dimensions of axis in dry vertebrae: a study in Indian population. Indian J Orthop 2015;49:583-8. 